Revista de Derecho

Universidad Católica del Norte

Sección: Estudios

Año 18 - No 1, 2011

pp. $119-145$

\title{
LA PERSISTENCIA DE LA PRUEBA LEGAL EN LA JUDICATURA DE FAMILIA
}

\section{Claudio Fuentes Maureira*}

RESUMEN: La reforma a los procedimientos judiciales ha supuesto cambios fundamentales en nuestro sistema probatorio; se ha pasado de un sistema de prueba legal a un sistema en donde predominan los principios de la libertad de prueba y la sana crítica. Estos suponen que el ejercicio de valoración de la prueba por parte de nuestros tribunales adquiere características y requisitos distintos, primordialmente se exige un análisis específico y concreto entorno al valor probatorio que le dio el juez a un determinado medio de prueba y qué razones lo apoyan. Esto difiere de lo que se espera de los jueces en el sistema del Código de Procedimiento Civil, en donde el análisis es más matemático y abstracto. El documento se centra en mostrar cómo, a pesar de que en materia de Tribunales de Familia se consagra el principio de la libertad probatoria y la sana crítica, existe jurisprudencia que muestra que aún los jueces aprecian las pruebas según la lógica del sistema de la prueba legal, método que no es compatible con los principios aludidos. Para fundamentar mi opinión me centro en dos tópicos: la utilización de criterios abstractos y generales para evaluar la credibilidad de testigos y la tendencia a exigir prueba cien por ciento indubitada para determinar la procedencia de un divorcio por culpa.

PALABRAS CLAVE: Tribunales de familia - sana crítica - prueba legal valoración de la prueba - credibilidad.

\section{Persistence of Legal Proof in Family Judicatura}

ABSTRACT: The reform to judicial procedure has posed fundamental changes to our proof system; we have gone from a system of legal proof to a system where the principles of liberty of proof and sound criticism prevail. These suppose that the exercise of proof valoration from our courts acquires different characteristics and requirements. Basically a specific and concrete

Abogado y Magíster en Derecho Penal y Procesal Penal por la Universidad Diego Portales. Profesor de Derecho Procesal y miembro del Departamento de Derecho procesal civil, (Chile) coordinador del Programa de Reformas Procesales y Litigación de la misma casa de estudios. Correo electrónico: claudio.fuentes@mail.udp.cl

Fecha de recepción: 26 de noviembre de 2010.

Fecha de aceptación: 8 de abril de 2011. 
analysis is demanded around the probatory proof that a certain judge gave to a determined means of proof and what reasons are behind it. This defers from what is expected from judges the Civil Procedure Code system, where the analysis id more mathematical and abstract. This document's focus is to show how, despite the fact that Family Courts consagrate the principle of liberty of proof and sound criticism, there is jurisprudence that demonstrates that judges still appreciate proofs according to the logic of the legal proof system, which is not compatible with said principles. I base my opinion in two issues: the use of general and abstract criteria to assess the witness' credibility and the tendency to require proof that is one hundred percent doubtless to determine the procedence of a divorce when the cause is the breach of basic marital duties.

KEY WORDS: Family courts - sound criticism - legal proof - proof valoración - credibility.

\section{INTRODUCCIÓN}

Como es de conocimiento público, nuestro sistema judicial en los últimos 10 años ha enfrentado reformas judiciales procesales bastante radicales; así, nuestro sistema procesal penal, de responsabilidad penal adolescente, familia y laboral se han visto sometidos a transformaciones extremas que alteran la forma como se hace justicia, pasando de procedimientos escritos, opacos y lentos a procedimientos que buscan las características opuestas: oralidad, transparencia y rapidez. Al menos de los mensajes presidenciales respectivos se desprenden esas características como su bandera de lucha ${ }^{1}$.

Ahora bien, estas transformaciones son mucho más que cambios cosméticos o "formales", se trata de alteraciones profundas a la lógica de las instituciones procesales que conforman estos procedimientos. Uno de estos casos paradigmáticos al que me refiero son las transformaciones al sistema probatorio.

Se observa que todas las reformas judiciales previamente mencionadas han hecho abandono del sistema contemplado en el Código de Procedimiento Civil de 1906 (en adelante "CPC") y han consagrado un sistema caracterizado por la libertad probatoria y la apreciación de los

Véase como ejemplo mensaje Presidencial de la Ley 19.968. "En primer lugar, se trata de tender, al igual que en materia procesal penal, hacia procedimientos que favorezcan la inmediación entre los justiciables y los jueces, instituyendo, en consonancia con el derecho comparado, un procedimiento que enfatice la oralidad por sobre la escritura. Ello favorecerá la publicidad y la imparcialidad del juicio jurisdiccional contribuyendo, así, a aumentar su legitimidad". 
medios probatorios en conformidad a la sana crítica. En otras palabras, se pasa de sistemas judiciales limitados en la discrecionalidad del juez, hacia sistemas judiciales que otorgan un voto de confianza en las capacidades de percepción, inteligencia y raciocinio de nuestros jueces: ahora son estos, y solo estos, los que dicen qué está probado y qué no.

Estos 10 años de reformas judiciales también han permitido adquirir conocimientos acerca de cómo transformar efectivamente el sistema judicial. La primera noción a este respecto es que el rol de la modificación legal ha cambiado. Inicialmente la redacción y aprobación del texto legal significaba la culminación de la reforma. Hoy nuestra experiencia nos permite aseverar que la culminación del texto legal es solo el principio y que muchas luchas y problemáticas se avecinan. La reforma legal es solo la base, el verdadero obstáculo es la práctica ${ }^{2}$, por eso algunos sostienen que la reforma judicial supone antes que todo una "batalla cultural". Esto, en términos reales implica que debemos ser capaces de cambiar la forma en cómo los operadores del sistema judicial hacen su trabajo, con el fin de que las nuevas ideas e instituciones pueden tener lugar en la realidad. Como se ve esta empresa no es menor.

El presente trabajo se trata básicamente de la idea antes expuesta, esto es, de cómo en la judicatura de familia, a cinco ańos de práctica judicial intensa, aún es posible encontrar algunos resabios de nuestros sistemas judiciales primigenios, especialmente en lo que se refiere a la apreciación de la prueba. Veremos que si bien la legislación de familia propugna el principio de la libertad probatoria y la sana crítica, estos principios al momento de apreciar el testimonio de ciertos testigos por parte de algunos jueces en causas de alta controversia, desaparecen, dando paso a la utilización de criterios propios de la prueba legal o tasada para apreciar o evaluar la fiabilidad de dichos testigos, cuestión que interpreto como una señal de falta de comprensión y de asentamiento de este "nuevo" sistema probatorio por parte de alguno de nuestros magistrados.

Para justificar mi hipótesis me detendré en los siguientes tópicos. En primer lugar, explicaré cuales son las lógicas que existen tras los sistemas de prueba legal y de sana crítica, lo que dará las bases para saber qué actitud se espera del juez en cada uno de ellos. Posteriormente explicaré cómo han sido consagrados en la ley 19.968 los principios de la libertad probatoria y la sana crítica, lo que reafirmará el cambio de paradigma que esta ley supone. Finalmente, mediante el análisis de algunas decisiones jurisprudenciales, presentaré cierta "evidencia" en base a la cual sostengo que para algunos jueces la prueba legal pervive. Posteriormente desarrollaré las consecuencias de aquello.

\footnotetext{
2 Centro de Estudios de Justicia de las Américas (2005). Reformas Procesales Penales en América Latina: Resultados del Proyecto de Seguimiento, CEJA, 229 pp., p. 12.
} 


\section{1) LA PRUEBA LEGAL Y LA LIBERTAD PROBATORIA}

\section{(1.1.) LA LÓGICA TRAS La PRUEBa LEGAL}

El surgimiento del sistema de la prueba legal o tasada está íntimamente vinculado al sistema procesal inquisitivo. Como se explicará a continuación, esta vinculación se debe a razones prácticas y políticas, más que a razones netamente jurídicas.

El punto de inicio del surgimiento de este sistema probatorio es el sistema judicial germánico, sistema que por las características del régimen político de la época se encontraba asociado a cada señorío feudal ${ }^{3}$. Este sistema probatorio operaba sobre la base de un conflicto judicial de carácter privado y su método de resolución decisivo no tenía por objetivo encontrar la "verdad" (material o formal) sino que determinar quién tenía la razón mediante el criterio de la fortaleza física ${ }^{4}$, en una ceremonia llamada "duelo". Asimismo, este sistema fue acompañado por las pruebas ordalías, que suponían la realización de desafíos que involucraban riesgos para la vida o la integridad física ${ }^{5}$, en las cuales la intervención divina era aquello que decidía el conflicto. Todo este sistema probatorio terminó con el surgimiento del sistema inquisitivo y la prueba legal ${ }^{6}$, por las razones que se explicarán brevemente.

Por un lado, la brutalidad del sistema judicial germánico, la discriminación en las garantías judiciales que algunos sujetos poseían, la posibilidad de establecer un reemplazante en el sistema de "duelo", entre otros acontecimientos permitió la deslegitimación y el descontento general hacia dicho sistema, para que fuese posteriormente superado por un sistema judicial propio de una cultura más avanzada (sistema romano-canónico) que a pesar del paso del tiempo era cultivado en las universidades e iglesias ${ }^{7}$. En este proceso contribuyeron especialmente dos fenómenos históricos, en primer lugar la proliferación del comercio y la necesidad de contar con registros escritos de las transacciones realizadas, lo que permitía contar con prueba preconstituida de alta calidad. En segundo lugar, fue en el Concilio de Letrán en el ańo 1215 en donde el Papa Inocencio III prohibió la participación de los clérigos en las ordalías, cuestión que en la práctica las tornaba inoperantes ya que era ne-

3 Maier, Julio B.J. (1996). Derecho Procesal Penal, Tomo I. Fundamentos, 2a ed., Buenos Aires: Editores del Puerto S.R.L., 883 pp., p 288.

4 Foucault, Michel (2005). La Verdad y las Formas Jurídicas, Barcelona: Editorial Gedisa, 2005, 184 pp., p. 71.

5 Vidmar, Neil / Hans, Valerie (2007). American Juries. The Veredict, Nueva York: Prometheus Books, 428 pp., pp. 22-24. También Foucault (2005) 72.

6 Cappelletti, Mauro (2006). El proceso Civil en el Derecho comparado, Lima: ARA Editores, 182 pp., pp. 99 y 100.

MaIER, Julio (1996) 289-291. 
cesario bendecirlas para contar con la intervención divina como criterio decisivo $^{8}$.

Desde un punto de vista político, el sistema inquisitivo y la prueba legal se impusieron igualmente. Así, la figura política del monarca absoluto, basado en la premisa de la concentración de poder requería para superar el sistema feudal funcionar sobre la base de instituciones que en la práctica le permitieran imponer su monopolio; el sistema inquisitivo pues era mucho más funcional a este esquema de concentración, ya que para operar no se encontraba restringido a unidades territoriales específicas y por sus propias características, la transformación del conflicto en una relación entre el Estado y el individuo, la persecución de oficio y la concentración de atribuciones en un funcionario estatal que desarrollaba la función judicial, permitía imponer el sistema político de concentración de poder.

Estas mismas características incidían claramente en la fisionomía del procedimiento judicial y del sistema de prueba. Debido a que la facultad de juzgar provenía del rey, el sistema recursivo operaba como un mecanismo de control del ejercicio de aquella facultad ${ }^{9}$. Para que dicho control fuera posible el sistema necesitaba reproducir el contenido de lo obrado ante las instancias superiores, determinándose que la forma más simple de lograr esto era por medio de la escrituración de los actos realizados. Dentro de la misma lógica, con el fin de limitar el poder de quien juzgaba se estableció el sistema de prueba legal, en donde en abstracto la ley determinaba el valor de los medios probatorios y las consecuencias de su valoración ${ }^{10}$. Así, por medio de la lectura del expediente, el juez que no presenció la prueba era capaz de determinar la correcta aplicación de las reglas que abstractamente valoraban esta.

Estas reglas que apriorísticamente determinaban el valor de los medios de prueba, las cuales derivaban de generalizaciones basadas en concepciones sociales y científicas que en aquella época eran válidas, y que reflejan dos relevantes ideas cardinales: primero, la idea de que el poder juzgar es del rey, no del juez y, segundo, una falta de confianza en el juez, especialmente en su capacidad para poder formar un juicio propio y acertado, que sea capaz de superar las complejidades de la realidad y las pruebas que fuesen presentadas frente a él ${ }^{11}$. De hecho el sistema de la prueba

\footnotetext{
8 BaLdwin, John (1961). "The Intellectual Preparation for the Canon of 1215 against Ordeals”. Speculum, Vol. 36, No 4, 613-636 pp., pp. 613-621. En español véase a TARUffo, Michele (2010). Simplemente la Verdad, Traducción de Daniela Accatino, Barcelona: Marcial Pons, 299 pp., pp. 13-18.

9 Maier (1996) 295.

10 Maier (1996) 298, Taruffo, Michele(2002). La Prueba de los Hechos, traducción de Jordi Ferrer, Madrid: Editorial Trotta, 542 pp., p. 393.

11 Sostiene Taruffo citando a Denti que "La racionalidad funcional del sistema de la prueba legal consiste principalmente en la exclusión de la arbitrariedad subjetiva de un juez que era
} 
legal en su versión más extrema funcionaba sobre una completa falta de relevancia acerca de la propia convicción del tribunal, a punto tal que los autores que han escrito sobre el tópico aseveran que los jueces simplemente se limitaban a tomar nota y nada más ${ }^{12}$.

Para que este sistema tuviese sentido en el contexto en que operaba, necesariamente la ley debía contemplar generalizaciones acerca de la prueba, método de proceder que era perfectamente consistente con la tendencia del pensamiento de aquella época, que se basaba en la escolástica y la filosofía aristotélico-tomista, cuya forma de proceder tendía al establecimiento de abstracciones, en donde de la directa observación de los fenómenos se concluía o derivaba, en palabras de Cappelletti, "verdades absolutas y a priori"13.

A mayor abundamiento, el sistema de la prueba legal suponía que, en materia testimonial, ciertas categorías de testigos no podían declarar frente a los jueces por su inmensa capacidad de inducir error en el tribunal $^{14}$ o el establecimiento de valoraciones apriorísticas entre los distintos medios de prueba. En el primer caso se trata de prohibiciones que suponían que un determinado testigo no era valorado de forma alguna por el tribunal, ya que el sistema judicial se privaba de la información que este pudiese dar ante la concepción general de que no era digno de ser creído. En el segundo caso se trata de testigos que eran efectivamente escuchados, pero el valor de su testimonio se encontraba sujeto a estas reglas generales.

Dentro de los primeros casos nos encontramos con los testigos que padecían de las incapacidades intelectuales como la minoría de edad y la extremada vejez ${ }^{15}$, también aquellos que tenían un interés, dentro de lo cual destaca el interés monetario, por amistad, por enemistad, por parentesco ${ }^{16}$, etc. En el segundo caso se trata de reglas como aquella que sostiene que es más verosímil el rico que el pobre "pues el pobre puede mentir por codicia o por promesa" 17 .

objeto de un amplio y difundido fenómeno de desconfianza social”. TARUfFo (2002) 389. Al respecto Cappelletti sostiene que la desconfianza se basaba en un temor de que el juez viese su imparcialidad comprometida por el contacto directo con las pruebas, de ahí a que se buscase evitar dicho contacto. CAPpelletti (2006) 95.

12 TARUfFo (2002) 392.

13 Cappelletti (2006) 97. En el mismo sentido Taruffo indica "Los juristas se enfrentan al problema de elaborar criterios para la valoración de las pruebas y lo hacen empleando poco a poco los instrumentos culturales generales de los que disponen: primero la lógica aristotélico-tomista y después las técnicas de la combinatoria y del análisis clasificatorio" TARUfFO (2002) 389

14 Bentham, Jeremías (2008). Tratado de las Pruebas Judiciales, 2a ed., Buenos Aires: Valleta Ediciones, 632 pp., p. 440.

Bentham (2008) 440.

Bentham (2008), 424.

Cappelletti (2006) 98. 
Lo relevante a destacar en este sistema de apreciación de la prueba es que el análisis del juez opera sobre generalizaciones en torno a la evidencia, en oposición a juicios específicos para el caso concreto y respecto de cada medio de prueba y su respectivo poder probatorio. Se trata de un sistema procesal que opera sobre la base de un juez que es percibido como funcionario judicial de poca significancia jurídica, ya por una falta de confianza en la labor judicial en su capacidad de sobrellevar las complejidades de la realidad probatoria, como en evitar su crecimiento como una figura que acumulase poder, esto en oposición al sistema de la libertad probatoria, como veremos a continuación.

\section{(1.2.) LA LÓGICA TRAS LA LIBERTAD PROBATORIA}

El sistema de la prueba legal que hasta esa fecha predominaba ampliamente en los sistemas del derecho continental fue posteriormente opacado gracias a un fenómeno histórico de gran envergadura: la revolución francesa y el surgimiento de la libertad de prueba ${ }^{18}$. Este sistema de prueba surgió, según Damaska, debido a factores jurídicos y políticos ${ }^{19}$ : los primeros consistieron en aceptar que el sistema de la prueba legal o tasada estaba basado en un nivel de abstracción de la realidad insostenible, en este sentido la libertad de prueba era básicamente un "acto de resignación” ya que el pensamiento científico de la época entendía que era imposible evaluar la prueba de antemano. Sin embargo, razones jurídicas fueron secundarias, realmente las razones políticas fueron aquellas de mayor relevancia. Así, debido a la desconfianza en los jueces en el uso arbitrario o contra la verdad de la ley, se dio paso a la necesidad de que quien determinara los hechos probados no fuera un juez, sino que hombres comunes (y analfabetos), en otras palabras, en la introducción en los sistemas del derecho continental del jurado.

Así, en el contexto del jurado el sistema de la libertad de la prueba no tenía límite alguno, vale decir, todos los medios probatorios en principio eran posibles de ser incorporados y la valoración de estos quedaba entregada a estas personas legas, que no tenían obligación alguna de entregar un fallo y de justificar su apreciación de determinados medios probatorios.

Con todo, lo que ocurrió después fue que los fallos pronunciados por los jurados resultaron ser peores que los de los jueces profesionales,

\footnotetext{
18 En este punto no está de más aclarar que el sistema de la prueba legal o tasada fue superado con distinta intensidad en materia penal que en materia civil, al respecto véase TARUffo (2002) 394 y ss.

19 Damaska, Mirjan (1995). "Free Proof and Its Detractors". The American Journal of Comparative Law, Vol 43, No 3, pp. 343-357, pp. 344 a 348.
} 
mostrando amplios niveles de discrecionalidad ${ }^{20}$ (recuérdese que este fue uno de los grandes temores de los revolucionarios). Esto llevó a la necesidad de compensar este factor por medio de introducir sistemas escabinados o mantener derechamente colegios de jueces profesionales y, desde el punto de vista de la libertad probatoria, si bien la prueba legal había desaparecido, la libertad de prueba perdería parte de su "libertad", dando paso a un sistema libre que no podía obviar los cánones de la racionalidad y de la experiencia ${ }^{21}$, los cuales suponían la necesidad de que el fallo fuera fundamentado, ya que la sola invocación por parte del tribunal de la libertad de prueba y la íntima convicción no era considerada como suficiente, debía asegurarse de alguna forma que los criterios de racionalidad fuesen respetados por los jueces ${ }^{22}$.

En este punto vale la pena detenerse brevemente en explicar las diversas aristas que componen la libertad de la prueba. En este sentido, es posible afirmar la libertad probatoria tiene dos dimensiones; la primera se refiere a los medios que pueden ser utilizados para probar los hechos controvertidos, sustanciales y pertinentes; la segunda se refiere a los criterios a los cuales puede apelar el tribunal para determinar la ocurrencia de aquellos hechos que se encuentran acreditados. La primera dimensión se denomina libertad en la admisión de medios probatorios, la segunda se refiere a la libre valoración.

La restricción a la libertad en la admisión de los medios probatorios, a diferencia de la libre valoración de la prueba, es una característica compartida por sistemas del derecho continental y del common law. En el caso de los sistemas procesales del derecho continental, se encuentran limitaciones que provienen del sistema de la prueba legal, que impiden el uso de ciertos medios probatorios para probar determinados hechos o que establecen mandatos que solo autorizan a usar un determinado tipo de medio de prueba para probar ciertas circunstancias. En el caso del derecho continental las restricciones a los medios de prueba se justificaban, como se mencionó, en la desconfianza hacia el juez. Un ejemplo muy interesante a este respecto es nuestra legislación procesal civil, específicamente aquello que se denomina la prueba sustantiva y que se encuentra regulada en los artículos 1698 y siguientes del Código Civil. En dicha regulación se encuentran diversas restricciones al uso de la prueba testimonial, por ejemplo aquella regulación (Art. 1708) que impide probar obligaciones que debían contar por escrito mediante prueba de testigos o la prohibición de probar mediante prueba testifical la existencia de obligaciones superiores a dos UTM (Art. 1709). El fundamento de dicha regulación,

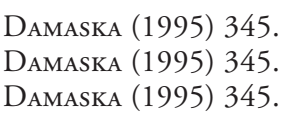


en palabras de Claro Solar, era: "la idea dominante, en el rechazo de la prueba verbal, que dictó la determinación del legislador chileno, fue la de evitar en lo posible una prueba que no daba garantías, ya que para rendirla se recurría a gentes que hacían de la prostitución del juramento una verdadera profesión (...) se desprende que la inseguridad de la prueba testimonial era la que principalmente motivó la disposición adoptada" 23 . Como se evidencia de la opinión de este reputado profesor, lo que justificaba la prohibición era una desconfianza casi a ultranza en la prueba testimonial, pero lo relevante, y que se puede leer "entrelíneas", era que esa desconfianza era para con el juez, quien no podría identificar a aquellas personas que lucraban con la "prostitución del juramento" de aquellas que no. Esa era la dificultad que se traducía en la inseguridad propia de la prueba testimonial, es decir, el riesgo estaba en que el juez pudiese ser engañado.

En el sistema del common law es posible sostener que las prohibiciones probatorias o exclusiones probatorias tienen un fundamento similar, en el entendido que el jurado, que era analfabeto, podía atribuir un valor probatorio excesivo a medios de prueba cuestionables (debido a su ignorancia), razón por la cual el sistema procesal debía de hacer un fuerte escrutinio acerca de los medios probatorios que eran presentados a este. Al respecto Cappelleti es claro: "Una vez admitida y asumida la prueba era bien difícil impedir al buen sentido y al espíritu de independencia de los jurados, sacar libremente de ellas las conclusiones. Más fácil era, en cambio, prescribir apriorísticamente toda una serie de exclusionary rules y de disqualifications, o sea inadmisibilidades" 24 .

En lo que se refiere a la segunda arista del principio de la libertad probatoria, esto es la libre valoración de los medios de prueba, es necesario aclarar que este principio es de contenido negativo, es decir, no demanda o exige un determinado sistema de valoración de la prueba (sana crítica o apreciación en conciencia), sino que simplemente su contenido se traduce en un claro mensaje del legislador hacia el juez de no recurrir al sistema de la prueba legal ${ }^{25}$. La sana crítica, como un método de valoración de la prueba que apela a la razón y a la explicitación de las motivaciones que soportan la decisión del juzgador, surge, como indiqué pre-

23 Claro Solar, Luis (1939). Explicaciones de Derecho Civil Chileno y Comparado. De las Obligaciones. Tomo XII, Santiago: Imprenta Nascimento, pp. 822, p. 735.

24 Cappelletti (2006) 101.

25 “(...) aunque el principio de la libertad valoración posee un claro significado negativo, también tiene un incierto significado positivo. Su significado negativo está determinado por la exclusión de las reglas de la prueba legal y por la libertad del juzgador para establecer el valor probatorio de los medios de prueba. La incertidumbre sobre su significado positivo deriva del hecho de que el principio no determina la forma en que el juzgador ha de llevar a cabo su valoración discrecional”. TARUFFO, Michele (2008). La Prueba, traducción de Laura Manríquez y Jordi Ferrer Beltrán, Barcelona: Marcial Pons, 324 pp., p. 136. 
viamente, cuando se intenta introducir parámetros de control acerca del razonamiento judicial. En este sentido, en lo que se refiere a los sistemas de valoración de la prueba, la sana crítica es una alternativa que por regla general va acompañando a la libre aportación de medios probatorios, pero no siempre será así.

Pues bien, desde el punto de vista del rol del juez, ciertamente la libertad probatoria supone una nueva confianza en las labores y capacidades de los magistrados, ya que, desde el momento en que las categorías apriorísticas son entendidas como un método que está impedido de abarcar la realidad, que presenta una visión del derecho y de la ley autista de toda otra ciencia o disciplina, no queda más que entregar al juez la confianza antes retirada, para que este por medio de la apreciación directa de la prueba y el contacto con las partes pueda analizar y "pesar" los medios probatorios presentados. La garantía está en la fundamentación de su decisión. En este sentido, es esta obligación la que demanda y permite que tengan sentido las expectativas de racionalidad que caen sobre la labor del juez, ya que la justificación de su razonamiento en un soporte es lo que permite y da legitimidad a la decisión a la que arriba, la posibilidad de que dicha decisión tenga pretensiones de intersubjetividad es lo que garantiza que esta será tomada en base a criterios racionales y se evitará la $\operatorname{arbitrariedad}^{26}$.

\section{2) EL SISTEMA PROBATORIO DE LA LEY 19.968}

La ley de Tribunales de Familia es una clara manifestación de que la distinción entre sistema inquisitivo y acusatorio tiene más validez en el mundo académico como una generalización metodológica, más que por su vigencia práctica. Es así que en el sistema ideado por el legislador en esta materia encontramos un híbrido, en donde conviven instituciones procesales, principios y criterios de valoración que son propios de estos

26 El mismo razonamiento es acogido por nuestro máximo Tribunal que indica: "Por otro lado, aunque como se ha sostenido, la estimación valorativa de las pruebas y las conclusiones fácticas de la sentencia son inatacables, esto no la libera del control del proceso lógico que debe seguir el juez en su razonamiento, precisamente a fin de custodiar la aplicación de las reglas de la lógica y la experiencia en la fundamentación. En este ámbito destaca la "garantía de la motivación, en cuya virtud se le da al juez libertad de apreciación pero, al mismo tiempo, se le obliga a correlacionar lógicamente los argumentos, demostrando su conclusión, para prevenir la arbitrariedad. (...) Que la exigencia de fundamentación surge no solo por disposición de la ley, como requisito formal de una resolución de la naturaleza de la que se trata, sino que también porque sustantivamente esta se presenta como única garantía tendiente a asegurar la justicia y legalidad de los fallos y a proporcionar a los litigantes los antecedentes que les permitan conocer los motivos de la decisión del litigio, a fin de evitar toda posibilidad de arbitrariedad". Corte Suprema de Chile. Sentencia de 2 de noviembre de 2009. Causa Rol 5.906-09. Considerandos Cuarto y Quinto. 
dos esquemas probatorios. Con todo, la opción del legislador es clara cuando se refiere a que el principio general en materia probatoria es la libertad de prueba (Art. 28) y que la valoración de esta es conforme a la sana crítica (Art. 32).

Me parece necesario, para los efectos de este artículo, detenerse un poco en cómo estos principios han sido consagrados en dicha ley, ya que mis críticas a la forma de proceder de algunos jueces de familia se fundamentan en buena parte en problemas de comprensión de estos.

Así, en lo que se refiere al principio de la libertad probatoria debe indicarse que está ampliamente recogido al señalar la ley que "todos los hechos que resulten pertinentes (...) podrán ser probados por cualquier medio producido en conformidad a la ley". Como se observa el tenor literal de la ley no circunscribe los tipos de medios de prueba a presentar, ni limita los hechos sobre los cuales puede referirse ${ }^{27}$.

Ahora bien, una segunda arista a considerar de la libertad probatoria es si la ley entrega u ordena una valoración en abstracto y obligatoria para el juez respecto de los medios de prueba incorporados. Al respecto se puede observar que la ley es bastante clara al entregar, particularmente ante prueba testimonial y pericial, autonomía a los jueces para efectos de valorar los medios de prueba. Respecto de la prueba testimonial, la ley indica que no existirán testigos inhábiles, esto es impedidos de declarar (Art. 40) a priori. Similar situación ocurre con los peritos cuando se menciona que los estos no podrán ser inhabilitados (Art. 48).

En segundo lugar, la ley envía un mensaje bastante explícito a los jueces de que el análisis que hagan de estos testigos y peritos debe ser concreto para efectos de determinar su valor probatorio. Es así que el mismo artículo 40 de la ley faculta a las partes a hacer actuaciones tendientes a cuestionar la credibilidad de un testigo, específicamente la ley habla de vínculos que afectasen su imparcialidad o idoneidad. Evidentemente este mandato de la ley solo puede realizarse mediante un análisis concreto de la prueba, ya que solo en ese escenario se sabrá si esos vínculos existen o no y de qué forma afectan la credibilidad del testigo. En el caso de la prueba pericial la propia ley entrega una regulación similar a la de los testigos, pero con la salvedad de que también puede cuestionarse el rigor científico o técnico de sus conclusiones. Nuevamente, para poder cuestionar el rigor científico de una conclusión se requiere realizar un análisis

27 Sin embargo, esta libertad probatoria presenta una relevante excepción, ya que si bien la ley no prohíbe algún medio de prueba en particular, el caso de la declaración de las partes presenta limitaciones. Es así que la ley 19.968 supone que la parte solo puede declarar a instancia de la contraria, no como un acto autónomo, operando con los mismos apercibimientos del CPC y dándole preeminencia al juez a efectos de interrogarla. Para un tratamiento detallado de este tópico véase a Marín Verdugo, Felipe (2010). "La Declaración de la parte como medio de prueba”. Revista Ius et Praxis, Año 16, No 1, pp. 125-170. 
concreto sobre qué está diciendo dicho perito, con qué método llegó a aquellas conclusiones y sobre qué información, todas estas cuestiones que solo pueden verificarse por medio de un análisis específico de su declaración e informe pericial.

Finalmente, en apoyo de este necesario examen específico y concreto que requiere la valoración judicial, es la misma ley 19.968 la que contempla en el artículo 54, que se refiere a Medios de prueba no regulados expresamente, que el único requisito para ser incorporado un medio de prueba no regulado es su capacidad de producir $f e$, en otras palabras, la ley entrega al juez la decisión de determinar cuándo dicho elemento probatorio es digno de ser creído, cuestión que solo puede analizarse concretamente.

Toda esta regulación es consistente con el otro principio cardinal del sistema probatorio de la ley de Tribunales de Familia, la sana crítica. Así, la ley en el artículo 32, intitulado valoración de la prueba, nos entrega el criterio de valoración, vale decir, bajo qué parámetros se juzgará la información aportada por el testigo o medio de prueba y nos indica cómo esta valoración debe reflejarse en el fallo en cuestión, al mencionar, que se debe individualizar los medios de prueba con los que se dan por acreditados los hechos.

$\mathrm{Al}$ respecto, la propia configuración de la sana crítica es lo que lleva a que la valoración que los jueces realizan de la prueba deba ser necesariamente concreta, como explicaré a continuación.

Como se sabe la sana crítica ha sido definida tradicionalmente como un sistema de apreciación de la prueba que constituye un término medio entre el sistema de prueba legal y el de la intima convicción o libertad probatoria $^{28}$. Se le alaba por ser flexible en la apreciación, aunque igualmente puede ser controlada.

La sana crítica supone valorar la prueba bajo criterios de racionalidad que son identificados por la doctrina como las máximas de la experiencia, los conocimientos científicamente afianzados y las reglas de la lógica ${ }^{29}$.

28 Cerda San Martín, Rodrigo (2009). Valoración de la prueba. Sana critica, Santiago: Librotecnia, 148 pp., p. 28.

29 Señala la jurisprudencia de tribunales de familia al respecto: "En conformidad con lo que prevé el artículo 32 de la ley No 19.968, los jueces de familia aprecian la prueba de acuerdo a las reglas de la sana crítica. Siguiendo a la doctrina y tal como reiteradamente lo ha resuelto este Tribunal, este sistema conduce al descubrimiento de la verdad por los medios que aconsejan la lógica y el criterio aplicado en juicio. Las normas, que la constituyen no están establecidas en la ley, de modo que se trata de un proceso intelectual del tribunal que analiza los antecedentes probatorios del litigio. Es una materia esencialmente de apreciación y, por lo mismo, cuya valoración corresponde privativa y excluyentemente a los jueces del fondo. La regla general es que la actividad de ponderación de las pruebas y, con ello, la fijación de los hechos del proceso, queda agotada en las instancias del juicio, a menos que los sentenciadores del grado al determinarlos hayan desatendido las razones lógicas, científicas, técnicas o de experiencia, en cuya virtud ha correspondido asignarles valor y determinar su eficacia". Segundo Juzgado de Familia de Santiago. Sentencia de 5 de mayo de 2010. 
Escapa del objetivo de este trabajo entrar a analizarlos pormenorizadamente, de hecho existe abundante literatura a su respecto ${ }^{30}$, pero estimo necesario realizar dos aclaraciones:

Primero, como se mencionó previamente, la libertad probatoria tiene un contenido negativo que niega al sistema de la prueba legal. Se sostiene que incluso la mera libertad probatoria no supone la entrega de ningún criterio específico de racionalidad a la cual debe aludir el juzgador al momento de apreciar la prueba ${ }^{31}$. Aquí es donde entra la sana crítica, en el sentido de que esta reafirmaría una libertad probatoria que demanda racionalidad en la valoración de la prueba al exigir los criterios previamente aludidos, pero ciertamente las máximas de la experiencia y los otros criterios están lejos de ser instrumentos de contenido preciso y pacíficos en la doctrina.

Segundo, incluso cuando estos criterios igualmente estuviesen claramente definidos se verá que la sana crítica no termina de resolver todo el trabajo que debe hacer el juez al momento de apreciar la prueba, de hecho si uno lo piensa bien, la sana crítica, más que decirle al juez cuándo debe dar por probado un hecho, es igualmente de contenido negativo, ya que le dice más bien cuándo no puede otorgar credibilidad a un determinado medio probatorio. Se trata en mi opinión de un límite a las conclusiones que los jueces pueden obtener respecto de la prueba que analizan, vale decir, no pueden llegar a conclusiones que sean contrarias a los conocimientos científicamente afianzados (v. gr. No puede afirmarse que la ley de gravedad no existe), las máximas de la experiencia (v. gr. No puede concluirse que una persona tenga mejor visión de noche que de día sin algún instrumento adicional a las capacidades de sus propios ojos) y a las reglas de la lógica (no puede en su razonamiento llegar de "A" a "C", sin pasar por "B"). Como se observa, se trata de prohibiciones en su razonamiento, límites a su análisis.

Causa RIT C-1652-2008. Considerando cuarto. En el mismo sentido Segundo Juzgado de Familia de Santiago. Sentencia de 16 de agosto de 2010. Causa RiT C-2754-2007. Considerando quinto.

30 Véase Cerda San Martín (2009) 35-69; Stein, Friedrich (1973). El Conocimiento Privado del Juez, traducción de Andrés de la Oliva Santos, Barcelona: Ediciones Universidad de Navarra, pp. 23 a 63, p. 38; TARUfFo (2006). Sobre las fronteras. Escritos sobre la Justicia Civil, traducción de Beatriz Quintero, Bogotá: Editorial Temis, 323 pp., pp. 107 a 140. Con todo, no deja de llamar la atención que los manuales más relevantes en lo referido al procedimiento ordinario según la ley de tribunales de familia den un trato marginal a un tópico de gran relevancia. En este sentido el libro de Baeza Concha y Pérez Cabrera dedica menos de una página a la valoración de la prueba. Baeza Concha, Gloria / Pérez Cabrera, Jaime (2008). Los Nuevos Tribunales de Familia. Procedimiento Ordinario, Santiago: LegalPublishing, 281 pp., pp. 125-126. A su vez el Manual de Tribunales de Familia de Silva Montes solo dedica media página a este tópico. Silva Montes, Rodrigo (2005). Manual de Tribunales de Familia, Segunda edición, Santiago: Editorial Jurídica de Chile, 170 pp., p. 31.

31 TARUFFo (2003) 666. 
En este sentido es perfectamente posible que un juez se encuentre ante dos medios probatorios que sean opuestos en su significado, por ejemplo dos testimonios que sostenga versiones contradictorias, y que igualmente dichas versiones no sean contrarias a la lógica, las máximas de la experiencia y los conocimientos científicamente afianzados. Por ejemplo, un divorcio en que ambas partes llevan testigos, unos que afirman que el demandado se fue de la casa por violencia intrafamiliar y fue observado golpeando a la parte demandante, mientras que otros sostienen que nunca golpeó porque se encontraba en otro lugar. Es perfectamente posible conciliar que ambas versiones pueden ser acordes a la lógica, acordes a las máximas de la experiencia y a los conocimientos científicos, en aquel caso entonces el juez debe recurrir a otro criterio para poder discriminar, los llamados estándares probatorios, los cuales pretender establecer un punto de suficiencia o un umbral ${ }^{32}$ que le permita decir al juez determinar cuándo existe suficiente evidencia para dar por acreditado un hecho.

Volviendo a nuestro tópico principal, la sana crítica supone un análisis concreto de valoración de la prueba puesto que los criterios que la conforman son cláusulas abiertas, cuyo contenido debe ser resuelto por el juez para ser útil en el caso concreto. Así por ejemplo, el caso más claro es el de las llamadas máximas de la experiencia, frase que sería acuñada por Friedrich Stein a comienzos de siglo pasado y dentro de las cuales el autor cita como ejemplo la naturaleza contagiosa de alguna enfermedad, lo que la costumbre exige en determinados negocios jurídicos, el sentido de determinadas expresiones, la rapidez de la comunicación entre Berlín y Nueva York, entre otras ${ }^{33}$. Todas estas premisas son consideradas como máximas de las experiencias, en otras palabras, se trata de premisas incontables, pero más importante aún, que variarán en cada caso concreto. Así, es perfectamente posible que en un caso de divorcio se apliquen distintas máximas de las experiencia que serán pertinentes según el conflicto en cuestión y los hechos que se alegan: en algunos casos será necesaria la máxima "las mamás no dejan a sus hijos pequeños sin supervisión", en otros será la premisa "las mamás generalmente se preocupan por sus hijos" o "es normal que los hermanos se culpen mutuamente de sus travesuras". La única forma en que un juez puede determinar qué máxima de la experiencia será utilizada como parámetro de valoración de la prueba será el caso en cuestión que está conociendo ${ }^{34}$.

32 Ferrer, Jordi (2007). La Valoración Racional de la Prueba, Barcelona: Marcial Pons 166. pp., pp. 139 y ss.

33 Stein (1973) 24

34 En un sentido afín Palomo indica: "En un sistema de valoración libre como el que postulamos es el juzgador quien determina las máximas de la experiencia que deben ser aplicadas, generalmente por tenerlas adquiridas gracias a su experiencia de vida, humana y cultural. Ya no vienen impuestas ni decididas por ley. De allí que bajo este seńalado sistema el juzgador se haga con un mayor protagonismo real. El juez chileno debe tener, en la mayoría de los 
Similar situación se da respeto de los conocimientos científicamente afianzados. En primer lugar, baste mencionar que la línea entre máximas de la experiencia y conocimientos científicamente afianzados es bastante borrosa. ¿En qué momento el resfrío dejó de ser provocado por bacterias y pasó a ser conocimiento popular que también es causado por virus? ¿En qué momento el VIH pasó de ser un "tipo de cáncer" a ser de conocimiento científico asentado que es un virus? Dicho eso es necesario aclarar que nuevamente será el juez, según los hechos planteados en el caso que conoce, quien determinará qué conocimiento afianzado será pertinente para ayudarlo a formar su convicción y evaluar la prueba.

\section{3) LA PERSISTENCIA DE LA PRUEBA LEGAL EN EL RAZONAMIENTO JUDICIAL}

La información presentada previamente pretende dejar claramente establecido en qué consiste, cuáles son las lógicas y qué se espera del juez ante los diversos modelos de sistemas probatorios. Como espero haber demostrado, cada sistema probatorio supone una actividad judicial distinta que se traduce en criterios de valoración y formas de valoración probatoria que son consistentes con la lógica y los principios probatorios que imperan un determinado procedimiento; en el caso de estudio, esto es la justicia de familia en su ley 19.968, el sistema probatorio escogido por el legislador está fuertemente inspirado, con una mayoritaria correspondencia normativa, por la libertad probatoria y por la sana crítica, lo que supone una forma de proceder del juez específica en la valoración probatoria que realiza, esto es, una valoración concreta del poder probatorio de cada medio de prueba, bajo los parámetros de la racionalidad.

Ahora bien, sostengo que a cinco ańos de la entrada en vigencia de la ley 19.968, es aún posible ver, en algunos fallos pronunciados por jueces de familia, una importante remisión a los criterios de ponderación y la forma de valoración del sistema de prueba legal, lo que, por supuesto, es inconsistente con las exigencias en el comportamiento y fundamentación que la libertad probatoria y la sana crítica demandan de estos, pero quizás más relevante, son una seńal de que el cambio cultural al que se aludía previamente está lejos de estar plenamente producido.

A continuación, gracias a la jurisprudencia, presentaré ejemplos de la persistencia de estas lógicas valorativas que estimo se traducen en dos manifestaciones concretas:

supuestos posibles, libertad para utilizar las máximas de la experiencia que estime más convenientes para aplicar a la valoración de la prueba”. Palomo VéLez, Diego (2010). Reforma Procesal Civil. Oralidad y poderes del juez, Santiago: Abeledo Perrot LegalPublishing 394. pp., p. 75. 
En primer lugar, la utilización de criterios abstractos y apriorísticos como parámetros para determinar el poder probatorio de la prueba testimonial.

En segundo lugar, la expectativa de los jueces de contar con información indubitada al momento de analizar la prueba.

\section{(3.1.) UTILIZACIÓN DE CRITERIOS ABSTRACTOS Y GENERALES PARA EVALUAR LA PRUEBA TESTIMONIAL}

Un sistema de prueba legal o tasada lidia con la prueba testimonial de dos formas posibles; se establecen ciertos tipos de testigos que no merecen ser escuchados por el tribunales (exclusión probatoria), en el caso de nosotros el CPC establece el sistema de las tachas y, la otra posibilidad, es definir el peso probatorio de dicho testigo, vale decir, el establecimiento de ciertas categorías de testigos que no deben ser creídos o que deben ser creídos en menor medida que otros por motivos definidos previamente. Ejemplos de estos casos son muchos, dentro de los más gráficos se encuentra aquel en que los ancianos son más creídos que los jóvenes "porque vieron más y pasaron más", que el rico debe ser más creído que el pobre porque "el pobre puede mentir por codicia o por promesa", el hombre debe ser más creído que la mujer "porque tiene el seso más cierto y más firme" 35 , entre otros. El problema de estos criterios es que se aplican al ultranza, vale decir, el sistema de la prueba legal no permite al juez apartarse de ellos por un lado, y por otro, al remitirse el juez a estos criterios evita tener que hacer un análisis concreto de por qué determinado testigo que cae en una de estas categorías no debe ser creído o su información es de menor confiabilidad que la proveída por otro declarante, en general los jueces ante un sistema de prueba legal se remitan a decir que dicho testigo "X" no es creído o confiable porque "padece" de una estas categorías generales y abstractas. Este método de proceder es incompatible con la sana crítica y sus exigencias según la ley de familia.

Al respecto es posible notar que en judicatura de familia algunos jueces operan sobre la categoría general del interés (cualquiera sea este: parentesco, laboral, económico, etc.) como un criterio que por el hecho de ocurrir es suficiente para restar valor probatorio a un determinado testimonio, sin entrar a analizar por qué en este caso concreto dicho interés afecta el testimonio, vale decir, no se explica de qué manera el vínculo lo hace inverosímil.

\footnotetext{
35 Ejemplos citados en Couture, Eduardo (2003). Estudios de Derecho Procesal Civil, Tomo II Pruebas en materia civil, tercera edición, Buenos Aires: Depalma LexisNexis, 329 pp., p. 133.
} 
Un primer ejemplo de esto se da en un caso de divorcio por culpa fundamentando en la causal establecida en el artículo $54 \mathrm{n}^{\circ} 2$ de la ley de matrimonio civil, esto es "Transgresión grave y reiterada de los deberes de convivencia, socorro y fidelidad", caso en el cual el demandante alegó que su ex pareja el año 2006 desapareció del hogar común por tres días sin saber de su paradero para posteriormente reiterar la conducta y establecerse la salida definitiva del hogar común de la demandada el año 2007. La demandada no contestó ya que no asistió a la audiencia preparatoria, por lo que se entendió que se oponía a todos los hechos. En la audiencia de juicio el demandante rindió prueba testimonial para acreditar la causal (tres testigos) todos los cuales eran presenciales, estaban contestes en la fecha de la separación y las circunstancias en que se produjo esta, con todo el tribunal indicó: "consecuentemente, la prueba testimonial rendida no es suficiente para acreditar la existencia de los hechos que justifiquen la causal invocada por considerar tales declaraciones carentes de imparcialidad"36-37.

En el análisis del juzgado de familia, este entendió que solo bastaba para justificar la falta de credibilidad de dos de los tres testigos el solo acudir a la relación de parentesco en abstracto, en oposición a determinar de qué forma el hecho de tener una relación de parentesco o de interés en este caso concreto afectaba su imparcialidad. Así indicó: "El segundo testigo, quien señaló trabajar en la empresa Driver Ltda. de la cual es socio accionista el demandante, se mostró igualmente incómodo al señalar como dato de

36 Juzgado de Familia de Rengo. Sentencia de 14 de abril de 2009. Causa RiT C- 6982008, Considerando $8^{\circ}$.

37 Un aspecto relevante a destacar, pero que va más allá de los objetivos de este texto, dice relación con la concepción tradicional de testigo. Así, por ejemplo, el Manual de Alex Carocca indica que una característica básica de estos es no tener interés en el resultado del juicio. Esta idea conduce también a atribuir a los testigos la característica de imparcialidad. Carocca Pérez, Alex (2003). Manual de Derecho Procesal. Tomo II, Santiago: Editorial LexisNexis, 367 pp., p. 238. Si bien en la teoría es posible hablar de testigos que no tienen interés en los resultados del juicio, en la práctica, especialmente en materia de tribunales de familia en donde los conflictos sueles involucrar familiares e hijos, no parece ser esta una definición útil, ya que necesariamente aquellas personas que tiene vínculos afectivos con alguna de las partes tendrán derechamente interés en el resultado. Es así que el hijo de la madre que sufre violencia intrafamiliar le interesa que su padre salga del hogar común o que la abuela que testifica en juicio de alimentos a favor de las necesidades de su nieta, tiene un claro interés en que estas se vean satisfechas y el padre sea ordenado a pagar. La consecuencia de seguir una definición muy literal de testigo, como aquella que he citado previamente, podría llevar a la conclusión de que ningún familiar cumpliría con las características de imparcialidad o de falta de interés con el resultado del juicio. Esta interpretación literal no parece ser razonable y por ello nuestros tribunales de familia admiten generalmente su testimonio. Con todo, la contracara de esto es que desde la perspectiva de la valoración de la prueba, asignar mayor o menor valor probatorio a un testigo en virtud de su sola imparcialidad o falta de interés con el resultado del juicio no parece ser del todo apropiado, considerando que aquí la realidad debe ser un factor a considerar. Este sería otro argumento por el cual mantener categorías de prueba legal al momento de valorar prueba testimonial supone un riesgo importante de privación de información útil basado en un mero peligro abstracto. 
individualización su lugar de trabajo, restándole credibilidad a su testimonio lo que además se refuerza al otorgar antecedentes poco precisos y vagos. La tercera testigo y hermana del demandante sin entrar a analizar el vinculo familiar que ya resta imparcialidad señaló en términos generales que la cónyuge se fue del hogar en Semana Santa del año 2007 y de ahi en adelante nunca más regresó, que se enteró por personas muy cercanas que tendría una pareja que mantiene hasta la fecha, que desde que se fue el padre se hizo cargo de las obligaciones del hogar y de los hijos, debiendo descuidar un poco su trabajo y que en la actualidad los tres hijos están viviendo con la madre pero no puede precisar desde qué fecha. Que desde que se fue se produjo un quiebre definitivo en la pareja y en la familia'38.

Respecto de este análisis se puede observar que en el caso del segundo testigo el primer antecedente que resta credibilidad es la existencia de un vínculo laboral, esto asociado a una incomodidad percibida al momento de dar su dirección laboral. Estas dos razones fueron aquellas que permitieron al tribunal entender que su testimonio no era imparcial, por lo cual poco confiable. En este análisis no se dilucida un razonamiento destinado a explicar por qué el hecho de existir este vínculo laboral no le permite al juez confiar en el testimonio, por ejemplo, no se indica que por el hecho de tener una relación laboral cercana se ha generado una relación de confianza y amistad entre el testigo y la parte (relación identificable), relación de amistad que ha sido descrita como muy cercana y que se ha traducido en aumentos de sueldos sistemáticos del testigo, entrega de bonos, presencia en cumpleaños, bautizos, etc. En otras palabras, no hay una razón concreta para este caso de por qué la relación laboral supone que la persona atestiguando mentirá. La misma deficiencia en la valoración se percibe al momento de analizar el razonamiento respecto de la tercera testigo, en donde el tribunal manifiesta claramente una asociación abstracta equivalente a "hermana/necesariamente parcial/poco confiable" $\mathrm{y}$ de hecho el tribunal sostiene, como una especie de regla general, que por el solo hecho de ser pariente ya hay una merma de imparcialidad, en su poder de convencimiento. No sabemos las razones por la cuales esta hermana necesariamente mentirá por su hermano, de hecho nuestro sentido común nos indica que hoy es posible que dos hermanos no necesariamente mentirán el uno por el otro. Asimismo, es también concebible que madres atestigüen contra sus propios hijos en causas criminales, por ejemplo ${ }^{39}$.

Carocca Pérez (2003) 238.

Esta idea de aplicar solamente criterios abstractos de forma absolutista no va de la mano con el sistema de la sana crítica. En palabras de Niceto Alcalá-Zamora "debe exteriorizar un juicio razonado que indique por qué motivos se acepta o rechaza, en todo o en parte, una opinión expuesta, mas sin que oscile de la sumisión ciega a la desconfianza infundada”, es decir, es posible creer parcialmente a un determinado testigo o medio probatorio, no se tra- 
Más explícito en este punto es el razonamiento seguido por la jueza del tercer juzgado de letras y familia de Chanco, quien conociendo de un divorcio por culpa según las causales $1^{\circ}$ y $2^{\circ}$ de la ley 19.947 desechó dicha pretensión. En efecto, el actor demandó por divorcio de cese de convivencia unilateral, mientras que la demandada presentó una acción reconvencional sosteniendo divorcio por culpa. La demandada presentó como testigos a sus hijos, al respecto el hijo mayor declara: "que los malos tratos tanto físicos y psicológicos, eran proferidos a él, la mayor parte del tiempo y que cuando su padre llegaba en estado de ebriedad, pateaba puertas, tomando en una oportunidad una picota, la que tiró sobre la cama en la que se encontraban acostados (...)" 40 . En sentido similar la hija menor indica: "separándose cuando ella tenía 4 años de edad, separación que se produjo por los malos tratos físicos y psicológicos propinados por su padre quien normalmente lo hacía en estado de ebriedad, golpeando incluso a su hermano cuando tenía entre 10 y 11 ańos de edad" ${ }^{1}$. Un tercer testigo indica respecto del demandado reconvencional que "era bueno para los traguitos, existiendo boches que terminaban con denuncias a carabineros" 42 .

Ante estos medios probatorios la jueza concluye que: "el tribunal desestimará la causal de divorcio culpa invocada por la demandante reconvencional, al resultar insuficientes las pruebas aportadas. En efecto, las probanzas allegadas por la actora reconvencional no resultan bastantes para hacer arribar a esta sentenciadora a la convicción de que concurre la causal (... $)^{\prime 43}$. Esta conclusión se basa en las características de los testigos que fundamentan la pretensión, estimándose que la relación de parentesco como causal en abstracto de falta de imparcialidad resta poder de convencimiento. A este respecto la jueza falla "toda vez que considerando la vinculación de parentesco o amistad que une a doña Marta Opazo Bustamante, con quienes declararon como testigos a su respecto, se ve afectado su nivel de credibilidad e imparcialidad necesaria, por lo que no resulta el medio de prueba idóneo para acreditar este punto"44.

En este segundo fallo se hace explícita la tesis que postula este trabajo, el análisis de la jueza no da razón alguna, ni siquiera intenta ex-

ta de todo o nada. Citado en Paillás, Enrique (2002). Estudios de Derecho Probatorio, 2a ed., Santiago: Editorial Jurídica de Chile, p. 24.

40 Juzgado de Letras, Garantía y Familia de Chanco. Siete de agosto de 2006. Causa Rit 22-2006. Considerando 5० I. Testimonial 1).

41 Juzgado de Letras, Garantía y Familia de Chanco. Rit 22-2006. Considerando 5o I. Testimonial 2).

42 Juzgado de Letras, Garantía y Familia de Chanco. Rit 22-2006. Considerando 50 I, Testimonial 6).

43 Juzgado de Letras, Garantía y Familia de Chanco. RiT 22-2006. Considerando $12^{\circ}$.

44 Juzgado de Letras, Garantía y Familia de Chanco. Rit 22-2006. Considerando $12^{\circ}$ (el destacado es mío). 
plicar por qué no son estos testigos prueba "idónea", sino que se remite a constatar el vínculo de parentesco para restar todo poder probatorio a tres testimonios que según consta en el fallo que he citado refieren a circunstancias específicas y a conductas puntuales por parte del demandado reconvencional. Las críticas que pueden ser dirigidas a este razonamiento son similares al caso previo, se requiere una explicación de cómo en el caso particular existen motivos fundados de que dicho parentesco hará que una persona mienta, nada de eso se encuentra en el presente fallo.

También es posible notar este tipo de razonamiento en los tribunales superiores. En un caso de demanda de cuidado personal del padre respecto de la madre el tribunal desechó la prueba pericial presentada por el solicitante en la cual se afirmaba que el niño presentaba el Síndrome de alienación parental por medio de un razonamiento abstracto y apriorístico cuestionando la imparcialidad del testigo. Al respecto la Corte resuelve: "Que la palabra "sindrome" significa un conjunto de sintomas caracteristicos de una enfermedad o un conjunto de fenómenos que caracterizan una situación determinada. El llamado Sindrome de Alienación Parental, del que no se tienen noticias aparte de los dichos del psicólogo Cristián Roberto Cejas Martínez, titulado de la Universidad La República en el año 1996, no incluido en el listado de peritos de la Corte de Apelaciones de Santiago, quien publicó artículos de su especialidad en el sitio web de "Amor de Papá", que preside el demandante, consistiría en un conjunto de sintomas derivadas de la influencia de un padre o madre en su hijo con miras a que este desprecie al otro progenitor, impidiendo asi el necesario vinculo entre el menor y su padre o madre. Pues bien, dicho "perito" afirma que no interrogó al niño de autos y su credibilidad, apreciado su testimonio de acuerdo con las reglas de la sana critica, es débil, desde que, ya se ha dicho, se trata de una persona que coopera con el movimiento liderado por el demandante"45.

En el presente ejemplo, si bien el tribunal hace un mayor esfuerzo por entregar razones que justifican que no creen en la labor del perito, estas motivaciones responden a una lógica más cercana a la prueba legal que al sistema de la sana crítica. En primer lugar, la Corte apela como criterio al hecho de que el perito no está incluido en el listado de peritos de la Corte de Apelaciones. Ahora bien, si se recuerda la regulación de la ley 19.968 esta indica que los peritos no pueden ser inhabilitados, pero más importante aún, que las partes pueden recabar informes de peritos de su confianza (Art. 45). En ninguna parte la ley de Tribunales de Familia contempla la necesidad de recurrir a peritos que sean parte de las listas de corte de apelaciones, sino que lo que la ley demanda es acreditar con comprobantes su "seriedad" e "idoneidad", lo que dice relación con

45 Corte de Apelaciones de Santiago. Sentencia de 22 de mayo de 2009. Causa ROL 5652009. Considerando $10^{\circ}$. 
asegurar, por cuestiones de economía procesal que el tribunal no perderá su tiempo escuchándolo, mas no con un registro de peritos "buenos" y peritos "malos o deficientes". De hecho la misma ley no contempla dentro de los requisitos de seriedad referencia alguna a ser parte de la lista de peritos de la Corte. Esta referencia a su falta de inscripción en el registro de peritos es una manifestación de que existen credibilidades preconcebidas en abstracto, lo que se opone al principio de la libertad probatoria y al método de valoración que supone la sana crítica. En segundo lugar, la Corte vuelve a juzgar la credibilidad del perito en base a consideraciones abstractas, específicamente interés, cuando entiende que por el solo hecho de cooperar con el movimiento amor de papá este perito, independiente de sus conclusiones, tendría una merma en su credibilidad.

\section{(3.2.) LA NECESIDAD DE PRUEBA INDUBITADA}

Según lo que se ha mencionado del sistema probatorio de la prueba legal, el valor probatorio que cada medio de prueba tiene, al ser entregado por el legislador, permite que dicho sistema opere con estándares probatorios absolutos, vale decir, con el estándar de la plena prueba. Dicho estándar supone que se encuentra absolutamente probado un determinado hecho, sin un margen de error, ya que es la ley la que indica cuando el juez debe darlo por probado, en este sentido el profesor Daniel Peńailillo indica: "es prueba plena (o perfecta, o completa) la que por sí sola basta para demostrar el hecho de que se trata (para producir convicción en el juzgador)" 46 .

El hecho de que el sistema de la prueba legal pueda aspirar a una certeza de $100 \%$ en sus conclusiones es plausible gracias a que el valor de los medios de prueba se fija de antemano, por ende las condiciones y requisitos del sistema de la prueba legal facilita esta "ilusión". Con todo, como se explicitó previamente, el surgimiento de la libertad probatoria como sistema probatorio es una consecuencia directa de la aceptación epistemológica de que el sistema judicial funciona necesariamente con márgenes de error, ya que cuenta con medios probatorios que no poseen la capacidad, a excepción de la confesión, de permitir concluir la ocurrencia de un hecho con un $100 \%$ de seguridad. Por tal motivo el sistema de la libertad probatoria, para funcionar adecuadamente, supone la definición de umbrales probatorios que se hagan cargo de estos márgenes de error ${ }^{47}$.

46 Peńailillo Arévalo, Daniel (1989). La Prueba en materia sustantiva civil. Parte general, Santiago: Editorial Jurídica de Chile 117 pp., p. 34.

47 Para una visión más detallada de los estándares probatorios véase a Fuentes Maureira, Claudio (2010). La Recepción de la Duda Razonable en el Sistema Procesal Penal en Chile, Tesis para optar al grado de Magíster en Derecho, Santiago: 51 pp., pp. 4 a 17, disponible en biblioteca Facultad de Derecho, Universidad Diego Portales. 
Estimo que una posible consecuencia de la pervivencia de la lógica de la prueba legal en materia de familia es la necesidad, particularmente en causas de divorcio por culpa, de contar con prueba 100\% indubitada por parte de los jueces, dicho de otra forma, los jueces esperan contar con antecedentes de un valor probatorio tan alto que se acerca considerablemente a la plena prueba, estándar que es ajeno a la lógica del sistema procesal que impera en la justicia de familia.

Un ejemplo de esta tendencia jurisprudencia lo constituye un caso de divorcio por culpa fundado en "adulterio" de la mujer respecto del marido; el actor rindió la prueba testimonial de sus cuatro hijos quienes contestes señalan que "vieron a su madre tomada de la mano con Pablo Acuña $y$ darse un beso en la boca, precisando la última que eso lo vio dos o tres veces. Todos manifiestan que su madre se habia enamorado de dicha persona. La primera testigo agregó que después de la separación de sus padres, su madre estuvo como dos o tres años con Pablo Acuña y compartían cama" 48 . Frente a estos antecedentes el Tribunal no acogió la solicitud de decretar el divorcio por culpa e indicó: "Que, como se puede apreciar, las declaraciones de estos testigos, apreciadas conforme a las reglas de la sana critica, aparecen insuficientes, por su vaguedad e imprecisión, para comprobar el adulterio imputado a la demandada, pues la única que señala que su madre compartía cama con Pablo Acuña es doña Claudia Zattera Bancalari, de donde pudiera eventualmente inferirse que ambos tendrian relaciones sexuales, pero se trata de un antecedente con escasa fuerza de convicción que por si solo no prueba el ayuntamiento carnal ${ }^{49}$ ".

En el caso en comento, existen cuatro testigos que vieron a su madre besarse con otro hombre distinto de su padre en más de una ocasión. Asimismo, uno de esos testigos indicó que vio a su madre compartir cama con otro hombre después de la separación de hecho. Estos antecedentes fueron entendidos como insuficientes por el tribunal, ya que, lo que el tribunal buscaba es un medio probatorio que probara el ayuntamiento carnal directamente y si bien estos medios probatorios eran prueba directa de conductas románticas de la madre con otro hombre, no lo eran de la relación sexual. Para decretar el divorcio por esta causal lo que el tribunal quiere es prueba inmediata del acto sexual mismo, una foto posiblemente. En este sentido, vale la pena preguntarse, siguiendo el criterio del tribunal, en qué casos podría contarse con un medio de prueba tan poderoso, que no admita dudas, si por la naturaleza de las relaciones sexuales extramaritales estas se desarrollan en forma secreta (sin mencionar que la misma fotografía podría ser excluida al haber sido obtenida sin el consen-

\footnotetext{
48 Corte de Apelaciones de Concepción. 9 de junio de 2010. Causa Rol 423-2009. Considerando $7^{\circ}$.

49 Corte de Apelaciones de Concepción. Causa Rol 423-2009. Considerando 8o el destacado es mío.
} 
timiento de la parte). El tribunal espera "plena prueba" al entender que por el tipo de acusación que se realizaba "tan grave en sus consecuencias patrimoniales y en el matrimonio, como la imputación de adulterio dirigida a la mujer requiere que se hagan mayores precisiones acerca de las circunstancias de tiempo y lugar en que ello ocurrió, no bastando decir que compartian cama si no se agregan antecedentes que demuestren fehacientemente el hecho que se imputa. El hecho de besarse y tomarse de la mano solo demuestra eso, no las relaciones sexuales" 50 .

Otro caso en que se refleja la expectativa de contar con plena prueba fue citado previamente, se refiere a la demanda reconvencional de divorcio por culpa, en la cual la demandante presenta dos testigos presenciales directos de los maltratos, los cuales no fueron creídos por ser parientes. $\mathrm{Al}$ respecto el tribunal concluye lo siguiente: "el tribunal desestimará la causal de divorcio culpa invocada por la demandante reconvencional, al resultar insuficientes las pruebas aportadas. En efecto, las probanzas allegadas por la actora reconvencional no resultan bastantes para hacer arribar a esta sentenciadora a la convicción de que concurre la causal (...)"51. Para justificar su decisión indica que "con las evidencias probatorias incorporadas, no se encuentra manifiestamente acreditado que existió atentados contra la vida o malos tratos graves contra la integridad física o psíquica de la cónyuge o de alguno de sus hijos (...)" 52

En este segundo ejemplo, tenemos que la parte presenta testigos presenciales directos de los hechos, que relatan circunstancias y sucesos específicos, los cuales no fueron creídos por ser parientes, esperando entonces el tribunal contar no solo con testigos directos de las acusaciones de Violencia Intrafamiliar, sino que sean personas completamente ajenas al conflicto, cuestión un poco difícil considerando que la violencia intrafamiliar se produce en el contexto de una familia por definición. Lo relevante es la expectativa probatoria, el tribunal solo está dispuesto a decretar la causal si cuenta con prueba infalible, realidad que escapa del sistema de la libertad probatoria y la sana crítica.

\section{CONCLUSIONES}

La decisión del legislador de establecer en la ley 19.968 de los Tribunales de Familia un sistema amparado en la libertad probatoria y en

50 Corte de Apelaciones de Concepción. Causa Rol 423-2009. Considerando 8º, el destacado es mío.

51 Juzgado de Letras, Garantía y Familia de Chanco. RiT 22-2006. Considerando $12^{\circ}$ (el destacado es mío).

52 Juzgado de Letras, Garantía y Familia de Chanco. Rit 22-2006. Considerando $12^{\circ}$ (el destacado es mío). 
la sana crítica no es solo una decisión acorde con las tendencias actuales en materia procesal, sino que resulta ser una decisión adecuada desde el punto de vista de contar con un sistema procesal acorde con las complejidades de la realidad, especialmente aquellos casos en que el tribunal se ve enfrentado a una realidad rápidamente alterable como lo es el conflicto familiar. Como mencioné al principio de este documento, el establecimiento de un sistema de prueba libre es un acto de confianza en las capacidades de los jueces, en el entendido de que el sistema del código de procedimiento civil establece una fuerte barrera con las partes y con la prueba en general. En un paralelo, puede afirmarse que el sistema de prueba legal se priva de mucha información (especialmente mediante las tachas), que puede ser relevante para el caso, bajo la excusa de una falta de confianza en la capacidad del juez de separar la paja del trigo, mientras que el sistema de la libertad probatoria permite que esa información sea conocida por el juez y confía en que este podrá sacar lo útil y pesarla según su mérito.

Dicho esto, el establecimiento de un sistema de libertad probatoria no solo supone un voto a favor de las capacidades de los jueces, sino que también supone el renacimiento de una obligación que en la actualidad se encuentra subdimensionada: una adecuada fundamentación de los fa$\operatorname{llos}^{53}$.

Siempre nuestro sistema ha exigido que las decisiones sean fundamentadas, pero basta ver sentencias de nuestros tribunales superiores para percatarse que en muchos casos dicha fundamentación es algo meramente formal. El caso más burdo es la resolución que confirmar una sentencia apelada, pero también es posible ver que esta falta de técnica judicial es consistente con un sistema de prueba legal. Así, si lo único que exige el legislador es que se verifique el numero de testigos y se indique que están contestes o que la escritura pública no se encuentra cuestionada, entonces, ciertamente, al menos en lo que se refiere a los hechos dados por acreditados, el estándar de una buena fundamentación es más bajo, se trata solo de revisar que se cumplan requisitos formales. Este panorama ha cambiado. El sistema de prueba libre y la sana crítica tienen su máxima manifestación en el razonamiento que el tribunal realiza cuando debe justificar los hechos que da por acreditados y en este aspecto nuestros tribunales de familia están en deuda, parcialmente al menos.

Los casos que he revisado como fundamento de mi postura en este artículo, permiten ver que al aplicar la lógica y los criterios de la prueba legal en un sistema de libertad probatoria, lo que está haciendo el juez es solo cumplir a medias con la expectativa que el sistema judicial tiene sobre él y su inteligencia. Decir que un testigo no es creíble porque es

53 Palomo Vélez (2010) 74. 
parcial y nada más, es una justificación deficiente en cuanto a la información que el tribunal se está privando de considerar al decidir la causa. En otras palabras, un tribunal debe tener muy buenas razones, específicas y concretas para desestimar en un 100\% los antecedentes aportados por un testigo, más aún si se trata de testigos presenciales. El sistema de la sana crítica si bien entrega al juez este voto de confianza, es un deber de este dar justificaciones claras, concretas y razonadas sobre por qué un testigo y la información que trae no son adecuados o suficientes.

Asimismo, el hecho de que algunos tribunales exijan para decretar divorcios por culpa un umbral probatorio altísimo también responde a la pervivencia de la prueba legal. Esto es un problema cuando nuestro sistema de tribunales de familia opera con libertad probatoria, ya que al exigirse estándares tan altos, quizás mucho más exigentes que más allá de toda duda razonable, se vuelve en la práctica imposible lograr una decisión que acoja este tipo de causal de divorcio, lo que trae como consecuencia una inoperatividad de la institución misma. La pregunta detrás es si el sistema de tribunales de familia está dispuesto a operar con exigencias probatorias tan altas, más aún si el hecho de operar con estas exigencias probatorias altísima necesariamente asegura que no se cometerán errores, ya que si el estándar o umbral es altísimo, muchos casos en donde si se produjo una causal válida de divorcio por culpa, quedarán "impunes" por las altas exigencias.

Es necesario que aquellos jueces que piensan que su convicción sobre la ocurrencia de los hechos se encuentra suficientemente fundamentada con solo hacer referencia a la expresión "según la sana crítica" entiendan que la mera mención es insuficiente; la sana crítica exige que los jueces estén a la altura que esta demanda de ellos: un análisis específico y fundamentado de la evidencia disponible y una explicación lógica, concatenada y comprensible para el público, no solo para el "telépata", que permita reproducir el razonamiento del tribunal. La persistencia de la prueba legal es una señal de que el procedimiento de tribunales de familia y los valores que este apoya están lejos de entenderse como asentados, solo una jurisprudencia exigente en estos aspectos permitirá avanzar.

\section{BibLiOgRAFÍA}

- Baeza Concha, Gloria y Pérez Cabrera, Jaime (2008). Los Nuevos Tribunales de Familia. Procedimiento Ordinario, Santiago: Legal Publishing, p. 281.

- Baldwin, John (1961). "The Intellectual Preparation for the Canon of 1215 against Ordeals”. Speculum, Vol. 36, No 4, 613-636 pp.

- Bentham, Jeremías (2008). Tratado de las Pruebas Judiciales, segunda edición, Buenos Aires: Valleta Ediciones, 632 pp. 
- Cappelletti, Mauro (2006). El proceso Civil en el Derecho comparado, Lima: ARA Editores, $182 \mathrm{pp}$.

- Carocca Pérez, Alex (2003). Manual de Derecho Procesal. Tomo II, Santiago: Editorial LexisNexis, 367 pp.

- Centro de Estudios de Justicia de las Américas (2005). Reformas Procesales Penales en América Latina: Resultados del Proyecto de Seguimiento, CEJA, $229 \mathrm{pp}$.

- Cerda San Martín, Rodrigo (2009). Valoración de la prueba. Sana critica, Santiago: Librotecnia, 148 pp.

- Claro Solar, Luis (1939). Explicaciones de Derecho Civil Chileno y Comparado. De las Obligaciones. Tomo 12 Santiago, Imprenta Nascimento, pp. 822.

- Couture, Eduardo (2003). Estudios de Derecho Procesal Civil, Tomo II Pruebas en materia civil, tercera edición, Buenos Aires: Depalma LexisNexis, 329 pp.

- Damaska, Mirjan (1995). "Free Proof and Its Detractors". The American Journal of Comparative Law, Vol 43, No 3, pp. 343-357.

- Ferrer, Jordi (2007). La Valoración Racional de la Prueba, Barcelona: Marcial Pons 166. pp.

- Foucault, Michel (2005). La Verdad y las Formas Juridicas, Barcelona: Editorial Gedisa, 2005, 184 pp.

- Fuentes Maureira, Claudio (2010). La Recepción de la Duda Razonable en el Sistema Procesal Penal Chile, Tesis para optar al grado de Magíster en Derecho, Santiago: 51 pp.

- Maier, Julio B.J.(1996). Derecho Procesal Penal, Tomo I. Fundamentos, segunda edición, Buenos Aires: Editores del Puerto S.R.L., 883 pp.

- Marín Verdugo, Felipe (2010). "La Declaración de la parte como medio de prueba”. Revista Ius et Praxis, Año 16, No 1, pp. 125-170.

- Paillás, Enrique (2002). Estudios de Derecho Probatorio, segunda edición, Santiago: Editorial Jurídica de Chile, 182 pp.

- Palomo Vélez, Diego (2010). Reforma Procesal Civil. Oralidad y poderes del juez, Santiago: Abeledo Perrot LegalPublishing, 394 pp.

- Peñailillo Arévalo, Daniel (1989). La Prueba en materia sustantiva civil. Parte general, Santiago: Editorial Jurídica de Chile 117 pp.

- Silva Montes, Rodrigo (2005). Manual de Tribunales de Familia, Segunda edición, Santiago: Editorial Jurídica de Chile, 170 pp.

- Stein, Friedrich (1973). El Conocimiento Privado del Juez, traducción de Andrés de la Oliva Santos, Barcelona: Ediciones Universidad de Navarra, 238 pp.

- Taruffo, Michele (2002). La Prueba de los Hechos, traducción de Jordi Ferrer, Espańa: Editorial Trotta, 542 pp.

- TARuffo, Michele (2006). Sobre las fronteras. Escritos sobre la Justicia Civil, traducción de Beatriz Quintero, Bogotá: Editorial Temis, 323 pp. 
- Taruffo, Michele (2008). La Prueba, traducción de Laura Manríquez y Jordi Ferrer Beltrán, Barcelona: Marcial Pons, 324 pp.

- Taruffo, Michele (2010). Simplemente la Verdad, traducción de Daniela Accatino, Barcelona: Marcial Pons, 299 pp.

- Vidmar, Neil y Hans, Valerie (2007). American Juries. The Veredict, Nueva York: Prometheus Books, 428 pp.

\section{JURISPRUDENCIA}

- Corte Suprema de Chile. Sentencia de 2 de noviembre de 2009. Causa Rol 5.906-09.

- Corte de Apelaciones de Concepción. 9 de junio de 2010. Causa Rol 423-2009.

- Corte de Apelaciones de Santiago. Sentencia de 22 de mayo de 2009. Causa Rol 565-2009.

- Segundo Juzgado de Familia de Santiago. Sentencia de 16 de agosto de 2010. Causa RIT C-2754-2007.

- Segundo Juzgado de Familia de Santiago. Sentencia de 5 de mayo de 2010. Causa RIT C-1652-2008.

- Juzgado de Familia de Rengo. 14 de abril de 2009. Causa Rit C698-2008.

- Juzgado de Letras, Garantía y Familia de Chanco. 7 de agosto de 2006. Causa RIT 22-2006. 